\title{
O governo Temer e a volta do neoliberalismo no Brasil: possíveis consequências na habitação popular
}

Temer Government and the return of the neoliberalism in Brazil: possible consequences for the popular housing

Mariana Barbosa de Souza[a], Tuize Silva Rovere Hoff[b] (i)

[a] Universidade Estadual de Ponta Grossa (UEPG), Ponta Grossa, PR, Brasil

[b] Unversidade de Santa Cruz do Sul (UNISC), Santa Cruz do Sul, RS, Brasil

Como citar: Souza, M. B., \& Hoff, T. S. R. (2019). Governo Temer e a volta do neoliberalismo no Brasil: possíveis consequências para a habitação popular. urbe. Revista Brasileira de Gestão Urbana, 11, e20180023. https://doi.org/10.1590/2175-3369.011.e20180023

\section{Resumo}

Este artigo objetiva descrever e exemplificar como o Brasil passa por uma transição do neodesenvolvimentismo para o neoliberalismo na segunda década do século XXI e apontar alguns possíveis desdobramentos desse processo nas políticas públicas de habitação. Considerando a afirmação de que, historicamente, o capitalismo no Brasil tem dependido de uma certa participação das classes populares para se desenvolver e analisando os Governos Lula e Dilma (2003-2016) em contraposição ao recente Governo Temer, pode-se chegar à hipótese de que o país passa por uma nova transição de regime econômico, de volta ao neoliberalismo adotado nos anos 1990 por Fernando Henrique Cardoso (FHC), e que essa transição pode ser um desafio ao desenvolvimento brasileiro, com consequências diretas na habitação popular. 0 artigo apoia-se em uma abordagem dialética e qualitativa, que é realizada mediante a análise e a interpretação dos referenciais teóricos e dos dados levantados com pesquisa documental.

Palavras-chave: Habitação popular. Neoliberalismo. Neodesenvolvimentismo. Brasil.

MBS é pós-doutoranda Geografia no Programa de Pós-graduação em Geografia (UEPG). É doutora e mestra em Desenvolvimento Regional e-mail: marisouza_10@hotmail.com

TSRH é doutoranda e mestra em Desenvolvimento Regional, e-mail: tuize.hoff@gmail.com 


\section{Abstract}

This article aims to describe and exemplify how Brazil undergoes a transition from neo-development to neoliberalism in the second decade of the $21^{\text {st }}$ century and to point out some possible developments of this process on public housing policies. Considering the assertion that historically capitalism in Brazil has depended on a certain participation of the popular classes to develop, and analyzing the governments of Lula and Dilma (2003-2016) in opposition to the recent Temer government, it is possible to find the hypothesis that the country undergoes a new transition of economic regime, back to the neoliberalism adopted in the 1990s by Fernando Henrique Cardoso (FHC) and this transition can be a challenge to Brazilian development, with direct consequences for the popular housing. The article is based on a dialectical and qualitative approach, which is carried out through the analysis and interpretation of the theoretical references, as well as the data collected with documentary research.

Keywords: Popular housing. Neoliberalism. Neo-development. Brazil.

\section{Introdução}

Embora o Estado brasileiro tenha se inserido no capitalismo tardiamente e de maneira dependente, o desenvolvimentismo foi verificado na modernização capitalista nas décadas de 1930-1960 (Boito, 2012; Bresser-Pereira, 2009). O neodesenvolvimentismo e o desenvolvimentismo são estratégias de desenvolvimento fundamentadas na teoria macroeconômica keynesiana, ideias que permitem que as nações em desenvolvimento desloquem o foco das propostas/pressões das nações desenvolvidas por mudanças e novas políticas econômicas. Outrossim, "a onda neoliberal e conservadora" que assolou o mundo na década de 1970 encontrou resposta no Brasil em 1980 e em outros países em desenvolvimento, em meio à crise da dívida externa. 0 país passava de um período ditatorial para a redemocratização, o que resultou em mudanças quando se fala em desenvolvimento.

A crise da dívida e a tomada do poder por militares apoiados "pelos industriais brasileiros e pelo governo norte-americano", nos anos 1960, acabaram por enfraquecer o movimento desenvolvimentista, dando lugar a governos conservadores e liberais ortodoxos. Pós-governo militar, o aumento da inflação e as constantes depreciações da taxa de câmbio reforçaram o descrédito ao regime desenvolvimentista. Além disso, o conceito de "nação" adotado no nacional-desenvolvimentismo foi gradualmente substituído pela tese globalista norte-americana, segundo a qual, “[...] na era da globalização, os estados-nação haviam perdido a autonomia e relevância: mercados livres em todo o mundo [...] seriam encarregados de promover o desenvolvimento econômico de todos [...]" (Bresser-Pereira, 2009, p. 79).

A lógica neoliberal que afetou a economia brasileira transformou também o espaço urbano das cidades, aprofundando desigualdades e influenciando o ordenamento do território. A lógica de mercado configurou cidades onde a gentrificação, a periferização e a segregação socioespacial emergiram notoriamente.

Atualmente, o país volta a se deparar com o que pode ser considerado um retorno às intervenções neoliberais de um governo levado ao poder a partir de um processo controverso de impeachment da presidenta Dilma Rousseff, eleita democraticamente. A partir dessas mudanças, analisam-se as políticas públicas urbanas, sobretudo as habitacionais, e suas modificações ao longo das diferentes estratégias econômicas. Essas políticas são diretamente afetadas pelo sistema neoliberal, pois obedecem, de modo prioritário, ao mercado da construção civil e à especulação imobiliária, visando ao lucro e ao fomento do setor em detrimento da mitigação dos problemas sociais urbanos. Apresenta-se uma tentativa de vislumbrar um panorama de como elas se adaptarão ao Governo Temer, principalmente diante do desafio constitucional que se impõe aos três entes federados: solucionar conjuntamente questões que se relacionam à habitação, levando em consideração o disposto, tanto na Constituição da República Federativa do Brasil (Brasil, 1988) quanto no Estatuto da Cidade (Lei no 10.257, promulgada em 10 de julho de 2001) (Brasil, 2001).

Este artigo é composto, além desta introdução e das considerações finais, de mais quatro seções. Na primeira seção, a partir de revisão, serão abordados o desenvolvimentismo e o neoliberalismo no 
Brasil. Em seguida, na segunda seção, serão apresentados os Governos Lula e Dilma e sua relação com o neodesenvolvimentismo. Após, na terceira seção, serão analisados os regimes econômicos governamentais e as políticas habitacionais para buscar, na última seção, uma melhor compreensão dos rumos da política neoliberal no Governo Temer no que diz respeito ao problema da moradia para a população de baixa renda no Brasil.

\section{O desenvolvimentismo e o neoliberalismo no Brasil}

O desenvolvimentismo brasileiro é uma estratégia que busca o crescimento econômico sem romper com o capitalismo, colocando o Estado como instrumento da ação coletiva, representando interesses dos empresários, da classe média e dos trabalhadores. Foi chamado assim porque apostava no desenvolvimento como ação política, e os chamados economistas desenvolvimentistas criaram a teoria econômica que, segundo Bresser-Pereira (2009), filiava-se a três escolas de pensamento complementares: a clássica de Smith e Marx, a macroeconômica keynesiana e a estruturalista latino-americana.

Em 1930, surgiu a possibilidade de que os recém-formados Estados nacionais autônomos viessem a fortalecer sua indústria, formando o que se chamaria de "burguesia nacional", a qual, associada aos funcionários governamentais e aos trabalhadores urbanos, daria início ao desenvolvimentismo no país (Bresser-Pereira, 2009). Apesar de contar com o Estado forte, o desenvolvimentismo brasileiro, assim como em toda a América Latina, não tornou o país livre da dependência das potências mundiais. A intenção era consolidar um Estado que definisse suas políticas e instituições, embora contasse fortemente com capital internacional e lidasse com a imposição de uma agenda conservadora.

Associadas às forças conservadoras estavam, de um lado, as oligarquias agrário-exportadoras, a burguesia e o capital financeiro. Do outro lado, estavam os movimentos sociais surgidos a partir da expansão urbana e industrial do Brasil, formados pela classe proletária, pelos novos empresários industriais e pela classe média composta de funcionários públicos, intelectuais, entre outros (Pereira, 2011).

Com o golpe militar, a aliança que conformava o desenvolvimentismo brasileiro rompeu-se. Em resposta à consolidação dos regimes nacionalistas, à crescente industrialização da América Latina, ao controle do mercado por parte dos Estados e à Revolução Cubana, forças hegemônicas interessadas em manter a dependência dos países em desenvolvimento, associadas com a força militar brasileira, ministraram golpes de Estado no Brasil, na Argentina, no Uruguai e no Chile, estabelecendo a ortodoxia como regime econômico (Bresser-Pereira, 2009).

Como neoliberalismo entende-se uma estratégia econômica que exalta o mercado, a livre-concorrência e a liberdade da iniciativa privada, rejeitando a intervenção estatal. Segundo Carinhato (2008), os neoliberalistas pregavam a superioridade do mercado sobre o Estado, destacando pontos específicos: as superioridades econômica e política, a constatação e crítica quanto à ação econômica do Estado e, por fim, no plano político, o privilégio do Estado a alguns, criando a dependência para muitos.

Apesar de prometer a retomada do crescimento econômico, as medidas conservadoras neoliberais se mostraram um fracasso, pois, embora tenham contido o aumento da inflação, o ajuste fiscal causou décadas de estagnação econômica, o que resultou em aumento do desemprego e dos índices de pobreza na região latino-americana (Pereira, 2011).

A partir da década de 1990, os países latino-americanos abriram seus mercados e seu capital e privatizaram seus serviços públicos, resultando em perda de autonomia, coesão e ausência de estratégias de desenvolvimento nacional. Um dos fatores que levaram à estagnação do país sob o regime econômico ortodoxo ou neoliberal foi a desconsideração aos efeitos colaterais da abertura do mercado. Apesar de atrair empresas estrangeiras para o solo nacional e da repatriação de recursos, com as privatizações também se instalou o desemprego, já que o objetivo principal dessas multinacionais era sanear as operações no país e, assim, reduzir empregos em vez de criá-los. 0 Investimento Direto Estrangeiro (IDE) em países em desenvolvimento não resulta em expansão da capacidade produtiva em 
longo prazo, e sim em obtenção de altos lucros em curto prazo ${ }^{1}$. Também não há interesse em investimentos a médio e longo prazo, como a construção de novas plantas por parte das empresas estrangeiras, mas a racionalização e a redução das antigas empresas estatais (Pereira, 2011).

Segundo Bresser-Pereira (2009), durante o Governo FHC, as políticas econômicas seguiram a cartilha neoliberal, mantendo o país em semiestagnação econômica, incapaz de competir com outros países. A política implantada por FHC foi a de estabilizar a economia com a alta de juros e adotar a poupança externa, o que levou à estabilização dos preços e, posteriormente, à estagnação econômica, impossibilitando a retomada do desenvolvimento do país (Mattei, 2011). Os resultados do plano econômico neoliberal no Brasil foram altas dívidas interna e externa - dos Estados-membro e do país e altos déficits públicos da nação, tendo como consequência direta, no início dos anos 2000, as mais altas taxas de desemprego já vivenciadas.

A respeito da transição do Governo FHC para o Governo Lula, Paulani (2008) afirma que a política adotada pelo ex-presidente Fernando Henrique trouxe severos resultados para o Brasil, sobretudo porque agravou o endividamento externo do país, tornando-se um tema de âmbito estrutural, enquanto o argumento com o qual se justifica a ortodoxia do começo do Governo Lula é de natureza conjuntural.

Nos primeiros anos do século XXI, houve a retomada do desenvolvimento nacional a partir do governo eleito do Partido dos Trabalhadores (PT). O Brasil teve um novo episódio em que a intervenção política dos trabalhadores resultou em fortalecimento do capitalismo (Boito, 2012).

\section{Os Governos Lula e Dilma e o neodesenvolvimentismo}

Ocorreram modificações na política brasileira que se consolidaram nesses governos. De acordo com Boito \& Berringer (2013, p. 31), houve uma alteração no centro do bloco no poder. Os autores afirmam também que o capital financeiro internacional e seus defensores, "[...] cujos interesses tinham guiado a ação do Estado brasileiro nos governos Collor de Mello (1990-1992), Itamar Franco (1993-1994) e Fernando Henrique Cardoso (1995-2002)", passaram a ser oposição ao governo.

Essa política, chamada neodesenvolvimentista, reuniu não só a burguesia interna brasileira, mas também a baixa classe média, o operariado urbano e o campesinato, incorporando a massa de trabalhadores desempregados, subempregados, trabalhadores por conta própria e os em situação de pobreza (Boito \& Berringer, 2013). Sua frente adversária seria então o neoliberalismo ortodoxo, o qual reunia o grande capital financeiro internacional e a burguesia a ele integrada - os grandes proprietários de terra e a alta classe média dos setores público e privado. A principal diferença entre os governos desenvolvimentista e neodesenvolvimentista está no papel do Estado, na promoção de poupança forçada e nos investimentos em infraestrutura econômica (Bresser-Pereira, 2009).

As políticas neodesenvolvimentistas adotadas foram no sentido de buscar o crescimento econômico e social brasileiro e o fortalecimento do capitalismo no país, contando com programas de transferência de renda e atendendo a interesses das classes dominadas, em vez de romper radicalmente com a política neoliberalista do bloco político no poder. Visando ao crescimento econômico, "[...] os governos Lula da Silva e Dilma Rousseff lançaram mão de alguns elementos importantes de política econômica e social que estavam ausentes nas gestões de Fernando Henrique Cardoso [...]" (Boito, 2012, p. 5). Entre esses elementos ausentes, o autor destaca políticas de transferência de renda e políticas de apoio às grandes empresas. Afirma ainda que, mais recentemente, o Governo Dilma modificou a política de "[...] juro cambial, reduzindo a taxa básica de juro e o spread bancário e intervindo no mercado de câmbio para desvalorizar o real, visando baratear o investimento produtivo a oferecer uma proteção muito tímida, é verdade - ao mercado interno [...]" (Boito, 2012, p. 5).

\footnotetext{
${ }^{1}$ Bruhn (2016) corrobora essa assertiva em sua tese de doutoramento, oportunidade em que analisou o Investimento Direto Estrangeiro (IDE) e sua relação com a política industrial. Ademais, esse também é o entendimento de Carminati (2010), que analisou o impacto do IDE na economia brasileira.
} 
Embora tenha promovido mudanças em relação às estratégias do governo anterior, o neodesenvolvimentismo adotado pelos governos do PT não empreendeu mudanças políticas e econômicas no sentido de amenização da dívida pública, proteção da indústria nacional ou mudanças no regime de exportações (Boito \& Berringer, 2013). Em contrapartida, as classes operárias realizaram importantes conquistas com os Governos Lula e Dilma.

A retomada do crescimento econômico fez com que as classes assalariadas tivessem uma significativa redução no desemprego, e os reajustes no salário mínimo trouxeram equilíbrio à desigual pirâmide salarial (Boito \& Berringer, 2013). A parcela de trabalhadores considerados marginalizados (com subempregos, sem garantias do emprego formal ou desempregados) e desorganizados socialmente teve sua inclusão no programa neodesenvolvimentista por meio das políticas de transferência de renda, como o Bolsa Família e o Benefício de Prestação Continuada.

Conforme Singer (2016), a opção política realizada para estimular a industrialização, embora não tenha grandes resultados no que diz respeito à industrialização e à sua relação com o PIB, é importante para sustentar ao menos um ensaio desenvolvimentista. Para o autor, esse argumento relaciona-se com a queda da presidenta Dilma Rousseff.

0 campesinato teve parte de suas reivindicações atendidas, como o financiamento à agricultura familiar e os programas de compras da produção camponesa. No entanto, o compromisso com o agronegócio fez com que os governos neodesenvolvimentistas ficassem aquém das reinvindicações de reforma agrária e desapropriações (Boito \& Berringer, 2013).

Quanto aos trabalhadores urbanos, um dos movimentos mais significativos durante os Governos Lula e Dilma foi o movimento em prol da moradia, organizado em diversas frentes reivindicativas. Entre as reinvindicações estavam a obtenção de moradia e a mudança na política de habitação. As conquistas desses movimentos encontravam-se no nível local, a partir da aquisição de imóveis e de terrenos urbanos em razão da ação direta e de medidas governamentais de políticas habitacionais (Boito \& Berringer, 2013).

Com os Governos Lula e Dilma, os programas de transferência de renda foram ações compensatórias. Embora persistisse o foco do critério e de seletividade, percebe-se que, por exemplo, o Programa Bolsa Família contribuiu positivamente para a pobreza absoluta, na medida em que inúmeras famílias possuíam apenas essa renda para sobreviver, conforme previsto na Política Nacional de Assistência Social (PNAS). "Com isso, o discurso da política neodesenvolvimentista se ampliara no país 'positivamente"'. (Silva et al., 2017, p. 5).

Compreende-se que o neodesenvolvimentismo brasileiro é oriundo de uma ação econômica que se esgotou e que, para Sitcovsky (2010, p. 237), “[...] revelou-se como parte da dinâmica entre produção e reprodução social do capital". Silva et al. $(2017$, p. 5) afirmam que, somado ao neodesenvolvimentismo, tem-se o ideário de "[...] empreendedorismo, autoemprego, autonegócio e da ideologia da sustentabilidade e a liberdade de escolha individual".

As melhorias em diferentes frentes da vida social da população possibilitaram alterações no discurso que versava sobre a desigualdade e o investimento em políticas públicas, inclusive nas políticas de habitação. Tudo isso foi uma tentativa de alinhar o governo econômico com o objetivo das massas, buscando conciliar o crescimento econômico com o desenvolvimento social (Silva et al., 2017).

Todavia, o capitalismo detém consequência estruturais, como o desemprego, o qual influi diretamente no caso dos programas sociais. Diante desse contexto, as políticas sociais estavam no foco da disputa econômica e política, possuindo como base a política a partir de um viés neodesenvolvimentista e o próprio Estado.

A partir do Governo Dilma, as políticas sociais estavam frágeis, e o país passou por um momento delicado, que surtiu substanciais transformações nas políticas habitacionais brasileiras, voltando sua orientação para o sentido mais econômico, sobretudo para o sentido liberal, ocasião em que se percebeu o resgate desse modelo.

Para Pinho (2017, p. 19), o esgotamento da gestão do Governo Dilma ocorreu em 2014-2015, diante de diferentes acontecimentos econômicos, sociais e cultuais, e marcou o "[...] esfacelamento da 
estratégia desenvolvimentista ancorada no crescimento econômico com dinamização do mercado doméstico de consumo de massas e inserção social dos setores populares." Para o autor, o Governo Dilma adotou uma política econômica de austeridade característica dos anos 1990. 0 resultado foi o estancamento dos investimentos produtivos a favor da obtenção de superávit primário para pagar juros da dívida pública e favorecer as práticas que rendiam do setor financeiro. "Este contexto sinaliza o resgate do tripé macroeconômico dos anos 1990 (austeridade fiscal, regime de metas de inflação e câmbio flutuante)." Findava-se, assim, a possibilidade social-democrata a partir do rompimento da coalizão política desenvolvimentista, que possuía as políticas sociais no centro da ação nacional de desenvolvimento. 0 Estado rendeu-se à política de austeridade fiscal, apontando para a resiliência do neoliberalismo, e isso se concretizou "[...] em cortes de programas sociais estratégicos (Minha Casa, Minha Vida), recessão econômica, agravamento do desemprego, deterioração da renda, retrocesso social da 'Nova Classe Média' (Classe C) e falta de recursos nas áreas de saúde e educação públicas."

Destaca-se que, de acordo com Bresser-Pereira (2014), esse período, denominado pelo autor Pacto Nacional-Popular de 2006 a 2014, não envolveu o primeiro mandato de Lula, tendo em vista que se encontrava dentro de uma perspectiva de um pacto liberalizante. Para o autor, o pacto ainda não se consolidou, pois é necessário que a população e os gestores encontrem uma forma de colocar os planos em prática, o que ainda não aconteceu no Brasil ${ }^{2}$.

Soma-se a essa concepção o pensamento de Singer (2018, p. 21), que afirma que a sociedade brasileira se encontra no limbo, em que os pobres podem deixar de ser pobres enquanto sujeitos, mas não como uma classe, porque a pobreza nunca pode deixar de existir. E, nesse contexto, o lulismo acabou quebrando em razão das contradições brasileiras, somado à Dilma, no âmbito ideológico roosveltiano. Embora tenha havido uma mudança do sub-proletariado para o proletariado, permaneceu uma pressão pelas condições de reprodução do capitalismo ao modo brasileiro.

A partir da concretização de 2016, o Governo Temer adotou medidas austeras a fim "[...] equacionar o problema da deterioração das contas públicas [...]", tais como "[...] a PEC 241/55 (PEC do teto de gastos públicos), a reforma trabalhista, a reforma da previdência e outras propostas que limitam os gastos sociais." (Pinho, 2017, p. 22-23).

\section{Os regimes econômicos governamentais e as políticas habitacionais}

Durante o Governo Vargas (1930-1954), foram implementadas medidas governamentais que visavam, ao menos na aparência, garantir moradia digna aos trabalhadores, defendendo as condições de trabalho dos assalariados urbanos. Entre as medidas mais importantes estavam o Decreto-lei do Inquilinato (1942), que congelava os aluguéis e regulamentava as relações entre locadores e inquilinos, e a criação das carteiras prediais dos Institutos de Aposentadoria e Previdência e da Fundação da Casa Popular, que deram início à produção de moradias subsidiadas. Para Bonduki (1994), a ação estatal marcou o momento em que a habitação foi assumida pelo Estado como uma questão social, dando início às políticas públicas habitacionais no país. Antes de 1930, as iniciativas para a habitação social podiam ser consideradas incipientes, uma vez que o Estado, fiel aos preceitos liberais, privilegiava o mercado privado e recusava-se a intervir de forma direta na construção de moradia para os trabalhadores. Nesse período, era intensa a produção habitacional voltada para a locação de moradia para os trabalhadores urbanos.

No ano de 1967, durante a ditadura militar, foi criado o Fundo de Garantia do Tempo de Serviço (FGTS). Formou-se uma estratégia de intervenção na questão habitacional, em que os recursos do FGTS e da poupança voluntária constituíam o Sistema Brasileiro de Poupança e Empréstimo (SBPE), que viria a subsidiar o Sistema Brasileiro de Habitação, por meio do Banco Nacional de Habitação (BNH) e de uma rede de promotores financeiros públicos e privados. Essa rede viabilizaria a implementação de

\footnotetext{
2 Bresser-Pereira (2014) indica sugestões para a promoção do desenvolvimento do Brasil, como: taxa de lucro que chame a atenção dos empresários para investimento; taxa de juros baixa para financiar a economia e aumentar a produção; taxa de câmbio competitiva; taxa de salário justa; taxa de inflação controlada.
} 
ações na área habitacional por meio de recursos estáveis, permanentes e independentes de oscilações políticas (Bonduki, 2008).

Apesar da existência de um mercado prévio de venda de apartamentos populares desde a década de 1920, foi somente a partir da formação do BNH que foi regulamentado o setor de construção de moradia de interesse social, vinculado ao governo e implementado por instituições públicas e privadas: "Foram criados também instrumentos financeiros como as sociedades de crédito imobiliário e as letras imobiliárias, compondo um Sistema Financeiro da Habitação (SFH)." (Rolnik, 2015, p. 281). Ainda no mesmo ano, foi editada a Lei de Incorporações Imobiliárias (Lei no 4.591, de 16 de dezembro de 1964) (Brasil, 1964).

A crise de 1980 deu origem a uma série de críticas ao conservador BNH. O desemprego, a consequente baixa arrecadação com retração dos saldos do FGTS e a inadimplência colocavam em xeque a constante alta das prestações financiadas. Além disso, a luta contra a ditadura militar e pelas eleições diretas transformou-se também em luta contra a instituição. Em 1986, logo após o fim do regime militar, o BNH foi extinto, dando fim também à política nacional de habitação. Desde a criação do BNH, existia um campo de convergência, já que a política influenciava as ações monetárias e fiscais do país. Também estava inserida em um contexto ideológico de combate ao "déficit habitacional" e era vista como um instrumento de incentivo à atuação da construção civil (Rolnik, 2015, p. 282).

Porém, apesar das críticas, o sistema financeiro habitacional ligado ao FGTS trouxe ganhos aos setores da habitação e da construção civil no Brasil. Segundo Bonduki (2008), foram financiadas cerca de 4,3 milhões de construções novas, das quais 2,4 milhões voltadas para o setor popular e contando com recursos do FGTS. Além disso, com recursos do Sistema Financeiro de Habitação (SFH) foi implementado o Plano Nacional de Saneamento (PLANASA), que foi responsável pela expansão das redes de água e esgoto nas principais cidades brasileiras, abastecendo por redes de água mais de $90 \%$ da população urbana.

Para Rolnik (2015), o período do início da década de 1990 até o Governo Lula, em 2004, foi marcado pela financeirização do sistema de habitação brasileiro, ampliando a participação do mercado financeiro no mercado imobiliário e criando produtos vinculados ao mercado de títulos. Isso significa que, de acordo com o neoliberalismo da época, para solucionar a questão habitacional, deveria haver uma modernização com a ampliação da oferta de moradia com baixo custo e a abertura de crédito a longo prazo. Rolnik (2015, p. 287) afirma que, para os defensores das políticas neoliberais, a mais eficaz política de habitação social "[...] era desenhar um marco regulatório confiável para o setor imobiliário, com o objetivo de atrair investidores em potencial e fomentar a oferta habitacional através de relações de mercado".

No Governo FHC, após 1995, houve uma tentativa de retomada nos financiamentos de habitação e saneamento com recursos do FGTS. Foram rejeitados os programas tradicionais, que eram sustentados pelo "[...] financiamento direto à produção de grandes conjuntos habitacionais e em processos centralizados de gestão [...]" (Bonduki, 2008, p. 78). Mas as mudanças realizadas não trouxeram benefícios reais ao sistema habitacional brasileiro: "O financiamento para aquisição de imóvel usado, que absorveu $42 \%$ do total de recursos destinados à habitação (cerca de 9,3 bilhões), é um programa com escasso impacto, não gerando empregos e atividade econômica." (Bonduki, 2008, p. 78).

A inobservância das necessidades habitacionais, somada às restrições de ordem macroeconômica adotadas no Governo FHC, limitou tanto o financiamento ao setor público quanto a participação dos agentes desse setor na execução das políticas de habitação, sobretudo no que se refere à urbanização de áreas precárias. A dificuldade de acesso a operações de saneamento e habitação com recursos do FGTS continuou vigente nas camadas de mais baixa renda (Bonduki, 2008).

Lula assumiu a presidência em 2002, e uma das primeiras iniciativas de seu governo, que vinha ao encontro de sua campanha política, foi a criação do Ministério das Cidades, órgão encarregado de formular a política urbana em nível nacional e fornecer apoio técnico e financeiro a governos locais, integrando as arenas das políticas de habitação, saneamento e transportes (Rolnik, 2015). Entretanto, o controle sobre os recursos de FGTS continuava sob a tutela da Caixa Econômica Federal, subordinada ao Ministério da Fazenda, dificultando o acesso aos recursos orçamentários e fazendo com que 
prevalecessem os programas criados pelo Governo FHC, sem priorizar a população de baixa renda (Bonduki, 2009).

Somente em 2005, após a II Conferência das Cidades, foram criados o Fundo Nacional de Habitação (FNH), como um fundo orçamentário, e o Sistema Nacional de Habitação de Interesse Social (SNHIS), que viria a exigir dos Estados-membros e dos municípios a criação de uma estrutura institucional, com fundo, conselho e plano de habitação para possibilitar o acesso aos recursos do FNH (Rolnik, 2015).

Salienta-se que, desde o princípio, o FNH encontrou forte oposição na equipe econômica ortodoxa. Somente em 2006, com a entrada de Guido Mantega - desenvolvimentista - no Ministério da Fazenda, a estratégia de crescimento econômico passou a ser a política dominante, com fomento à aquisição da casa própria nas classes mais pobres. Se, desde o início do mandato de Lula até o primeiro mandato da presidenta Dilma, o consumo foi tido como mola propulsora de crescimento econômico, a implantação do Programa Minha Casa, Minha Vida (PMCMV) veio como medida fundamental nesse sentido (Rolnik, 2015).

O PMCMV surgiu em 2009 como um pacote de medidas habitacionais, elaborado, inicialmente, pelo governo em conjunto com empresários e investidores da construção civil com o objetivo de fomentar o crescimento econômico por meio de geração de emprego e renda em um cenário desfavorável pós-crise imobiliária americana (Rolnik, 2015). Previsto como viabilizador de 200 mil moradias voltadas para a faixa de 4 a 10 salários mínimos, com a intervenção presidencial acabou aumentando sua meta para cerca de 1 milhão de unidades habitacionais, parte delas totalmente subsidiadas, abarcando as classes mais pobres (PMCMV - faixa 1).

O programa foi lançado em março de 2009, após protestos de setores organizados da sociedade civil, como os movimentos pró-moradia, sem-terra e pequenos municípios, quando o governo abriu espaço para a participação desses segmentos na discussão sobre sua ação efetiva. Em sua versão final, o PMCMV contava com as seguintes modalidades: MCMV-Entidades, prevendo subsídios que seriam destinados à produção de moradias por associações e cooperativas; Programa Nacional de Habitação Rural, para construção de casas na área rural, destinadas a pequenos agricultores familiares, cooperativas rurais, reassentamentos rurais etc.; MCMV-sub-50, destinado aos municípios com menos de 50 mil habitantes; e o "carro-chefe" do programa, o MCMV-Empresas, que apresentava condições específicas para variadas faixas de renda, com valores distintos para os subsídios, os mecanismos financeiros e os valores das unidades habitacionais a serem produzidas (Rolnik, 2015). A definição dos beneficiários ficaria por conta dos governos locais, com cadastros. No caso do MCMV-Empresas, os moradores contemplados seriam obrigados a pagar uma taxa correspondente a $5 \%$ da renda familiar para a Caixa Econômica Federal, responsável por comprar as unidades da empresa encarregada de realizar a construção.

Uma das grandes alterações que o PMCMV trouxe em relação aos programas de construção de habitações anteriores foi a inclusão da faixa 1, voltada a famílias com renda mensal de até 3 salários mínimos, que representavam 60\% do déficit habitacional brasileiro em 2010 (Guerreiro, 2015).

É importante salientar que o PMCMV abriu um espaço para a inciativa privada, inédito na política habitacional brasileira (Guerreiro, 2015), deixando ao seu comando operações, como busca, negociação e incorporação da terra, produção e aprovação dos projetos, construção e legalização, sendo que grande parte dessas responsabilidades ficava a cargo do setor privado, "[...] pois o programa retira qualquer risco do mercado de habitação popular, principal fator para o afastamento do capital privado em épocas anteriores, abrindo um campo anteriormente fechado para a acumulação." (Guerreiro, 2015, p. 4). Assim, o poder público passou a atuar como regulamentador do programa, definidor de repasse, aprovador dos projetos, fiscalizador das obras e indicador da demanda (Guerreiro, 2015).

Do ponto de vista do crescimento econômico, a estratégia governamental neodesenvolvimentista para a habitação foi bem-sucedida, angariando apoio de diversos setores da sociedade. Houve influência do êxito econômico do programa na eleição da presidenta Dilma Rousseff em 2010 e em sua reeleição em 2014, quando foram lançados o PMCMV 2 (2011) e o PMCMV 3 (2014).

Segundo Rolnik (2015), o Ministério do Planejamento afirmava, em 2014, que o programa já havia contratado 3,5 milhões de unidades e entregado cerca de 1,7 milhão de casas ou apartamentos. Apesar 
do sucesso como política neodesenvolvimentista de fomento ao setor da construção civil e da economia, o PMCMV não promoveu mudanças estruturais necessárias à realidade urbana brasileira: "Seguimos enfrentando a carência de espaços públicos de qualidade e acessíveis a todos, a existência de áreas densamente povoadas sem redes de infraestrutura básica e transporte, o aumento da segregação espacial das classes populares [...]" (Cardoso \& Jaenisch, 2017, p. 3).

Durante os governos petistas, a política habitacional acabou por se destacar na agenda governamental. Segundo Cardoso \& Jaenisch (2017), o volume de subsídios destinados a essas políticas foi o maior desde o BNH, permitindo, inclusive, que setores de baixíssima renda, até então excluídos da ação governamental, acessassem financiamentos habitacionais. Porém, é importante salientar que os grandes beneficiados com a política pública habitacional do PMCMV foram o setor imbiliário e as empreiteiras, tornando o setor privado protagonista.

As consequências urbanas do poder decisivo do mercado da construção civil sobre as políticas públicas habitacionais foram a padronização das construções, a ampliação da escala em nome da lucratividade, a periferização derivada da busca por terrenos mais baratos pelas construtoras e a adoção da tipologia de condomínios fechados para os novos conjuntos habitacionais de interesse social, conforme demonstram os estudos de Alvarenga \& Reschilian (2018) e de Pequeno \& Rosa (2016).

Apesar dos efeitos colaterais (Rolnik, 2015), o PMCMV deve ser considerado como um importante avanço para as políticas públicas habitacionais, com investimentos voltados para um setor da população pouco beneficiado com tais políticas e obtenção de moradia por grande parte da população mais pobre. Os subsídios empregados pelo governo para a obtenção de moradia pelas classes mais baixas tiveram um volume de investimentos inédito na história política brasileira, e a ampliação e o barateamento do crédito imobiliário para a compra de imóveis por setores de renda intermediária foram inegáveis. Além disso, ainda que não tenha promovido importantes modificações na reprodução da segregação e do padrão que reafirma as periferias como lugar dos pobres nas cidades, o PMCMV proporcionou um processo de urbanização cumulativo (Rolnik, 2015), que, comparado com contextos anteriores, atenuou a precariedade das periferias. Além disso, o programa modificou as condições de inserção urbana da habitação de interesse social, que, embora continue a ocupar áreas periféricas, são áreas contíguas à malha urbana, não apresentando o mesmo nível de isolamento urbano que os conjuntos habitacionais implementados por meio das políticas públicas anteriores ${ }^{3}$.

\section{O Governo Temer: política neoliberal na habitação?}

Em um contraditório e inconstitucional processo, a presidenta eleita Dilma Rousseff sofreu impeachment em abril de 2016. Anunciava-se o fim do ciclo petista de governo e o possível abandono das estratégias neodesenvolvimentistas de crescimento econômico. Segundo Bresser-Pereira (2011), o impeachment e a tomada do poder pelo PMDB (Partido do Movimento Democrático Brasileiro) de Michel Temer trariam uma guinada ao neoliberalismo e consequente estagnação econômica aos moldes dos anos 1990.

Foram tomadas medidas no sentido de mudar a direção das estratégias econômicas para outras claramente liberalizantes. A primeira reforma realizada foi a Proposta de Ementa Constitucional (PEC) no 241/2016, a qual foi aprovada em 15 de dezembro de 2016 (Emenda Constitucional no 95). Com o argumento de retomar o crescimento econômico, o Governo Temer limitou constitucionalmente os gastos públicos por 20 anos, diminuindo o Estado e impedindo que o sistema constitucional de proteção social (que inclui saúde, previdência e assistência sociais) funcionasse de maneira adequada às necessidades da população.

Para Rossi \& Mello (2017), ao pensar exclusivamente no limite do crescimento do gasto primário, o governo deixou de combater um dos principais “[...] sorvedouros de recursos públicos nos últimos anos:

\footnotetext{
${ }^{3}$ Esse entendimento também é reforçado por Alvarenga \& Reschilian (2018) e por Pequeno \& Rosa (2016).
} 
as desonerações fiscais, a sonegação e o pagamento de juros nominais, que responderam por mais de 8\% do PIB em 2015", praticamente o mesmo valor gasto com toda a Previdência.

Outra importante mudança proposta foi a chamada "reforma da previdência", ou a PEC 287/2016, que previa o aumento do tempo mínimo de contribuição de 15 para 25 anos e exigia ainda 49 anos de contribuição previdenciária para acesso ao benefício integral. Essa medida viria a diminuir consideravelmente o sistema previdenciário.

Ainda no mesmo sentido de diminuição do Estado brasileiro, foram retiradas da Lei de Diretrizes Orçamentárias (LDO) do ano de 2017 outras importantes metas sociais. Na contramão do FMI, que ressalta a importância de programas de distribuição de renda, o Governo Temer "[...] tenta apagar esse termo da trajetória brasileira para os próximos anos. A pedido do presidente, a Comissão Mista de Orçamento do Congresso Nacional alterou o texto que trazia os objetivos do Projeto de Lei de Diretrizes Orçamentárias (LDO) de 2017". (Rossi \& Mello, 2017).

Ainda, conforme os autores, foram excluídos termos que comprometiam a administração pública federal a assegurar a "distribuição de renda", o "[...] fortalecimento dos programas sociais" e a execução de "políticas sociais redistributivas [...]" (Rossi \& Mello, 2017).

Dentro do novo regime de austeridade estavam previstas privatizações, mudança do marco regulatório do pré-sal, retirando o direito da Petrobras de ser operadora única desses campos, e ainda aprovação da Lei Ordinária (Lei no 13.429, de 31 de março de 2017 (Brasil, 2017), Projeto de lei no 4.302/1998 do ex-presidente FHC), que permitia terceirizações de trabalhadores para todas as atividades (Brasil, 1998). Para o governo, era uma tentativa de atrair investimentos e facilitar a geração de empregos, porém, para os trabalhadores, representava uma fragilização nas relações trabalhistas e nos direitos conquistados historicamente.

Nesse contexto, a habitação de caráter popular já sofria algumas alterações em relação ao governo petista. A extinção da modalidade Entidades ${ }^{4}$ do PMCMV representou uma ruptura com o compromisso social do governo anterior. O MCMV-Entidades veio para alcançar a camada mais pobre da população. Com o seu cancelamento, famílias que lutavam há décadas pela conquista da casa própria voltaram a ficar desamparadas. De acordo com Maricato (2016), essas ações demonstram o caráter ideológico cruel e revelador presente na gestão de Temer. Ademais, "[...] essa modalidade abre possibilidades de melhores projetos de arquitetura e engenharia por meio de assessorias técnicas, prevista em lei, além de permitir à própria comunidade construir o empreendimento no todo ou em parte [...]" (Maricato, 2016). Para a autora, existe no Governo Temer uma tendência a investir nas camadas mais altas do mercado da construção civil, visando fomentar essa indústria e resgatar ações praticadas durante a ditadura militar no Brasil: concentração de investimentos nas altas camadas do mercado econômico. Para Maricato (2016), "[...] os que mais precisam de moradia ficariam de fora”.

A autorregulação do mercado se fazia presente. Além da usual falta de interesse em investir nas camadas mais pobres da população, havia ainda a reconhecida tendência mercadológica de investir em terra mais barata para a construção desse tipo de moradia. Essas terras ficam normalmente afastadas da malha urbana e do centro das cidades, carentes de infraestrutura e de serviços públicos (Maricato, 2016; Rolnik, 2015). Esse tipo de empreendimento acaba por intensificar o fenômeno da segregação urbana $^{5}$, trazendo novos problemas sociais.

Outra medida do Governo Temer em relação à política habitacional brasileira foi a revisão dos limites de renda atendidos pelo PMCMV e dos valores dos imóveis passíveis de aquisição com utilização do FGTS. Com as novas medidas, o limite dos imóveis a serem financiados com o fundo passou de $\mathrm{R} \$ 950$ mil para R\$1,5 milhão, e o teto da renda familiar para obtenção do financiamento via PMCMV

\footnotetext{
${ }^{4}$ A extinção se deu mediante a reedição da Portaria no 173, de 10 de maio de 2016. Antes da reedição, a Portaria autorizava a contratação de 11.250 moradias da modalidade Entidades do PMCMV (Brasil, 2016a). A alteração foi concretizada mediante a assinatura da Portaria no 258, de 16 de junho de 2016, pelo Ministro Bruno Araújo (Brasil, 2016b).

${ }^{5}$ Embora a Escola de Chicago tenha sido a pioneira no que diz respeito à compreensão do termo "segregação", ele foi apropriado de Villaça (2011), que assevera que as camadas mais pobres da população tendem a ter menos acesso aos bens e serviços públicos e a ocupar as piores localizações dentro da cidade, o que pode acontecer por meio de deslocamentos involuntários provocados pelo mercado da especulação imobiliária.
} 
passou de R \$ 6,5 mil para R 9 mil. Segundo informações da presidência da República, o aumento nos valores beneficiaria a classe média, facilitando o acesso aos financiamentos e o aumento do número de residências a serem custeadas, o que traria aquecimento ao mercado imobiliário. Porém, com essas alterações, segundo Rolnik (2017), as políticas públicas de habitação para as camadas mais pobres ficam prejudicadas. A autora afirma que o Estado passa a privilegiar as camadas mais altas da população sem criar políticas para as famílias de renda mais baixa.

Em relação ao FGTS, foi liberado o saque de contas inativas até dezembro de 2015, o que poderia servir como fomento para o consumo, mas acabou por esgotar ainda mais a única fonte de financiamento para os programas habitacionais e de saneamento nacionais. Ressalta-se que, desde a criação do $\mathrm{BNH}$, extinto posteriormente, o financiamento de casas e de apartamentos se dava a partir de recursos do FGTS, fundo de recolhimento obrigatório para os trabalhadores formais. 0 FGTS funciona tanto como uma poupança para o trabalhador quanto para financiar a habitação social e o saneamento no Brasil. "Como se trata de um dinheiro que o governo toma emprestado com juros muito baratos [...], o fundo pode viabilizar, em tese, o financiamento de produtos acessíveis para os mais pobres" (Rolnik, 2017).

Esses fatores se refletirão largamente na realidade habitacional do país, e, mais uma vez, o mercado imobiliário será alavancado em detrimento da solução do déficit habitacional brasileiro e dos problemas sociais por ele ocasionados. Existem ainda indícios de encolhimento do setor imobiliário e da construção civil em particular, uma vez que são altamente dependentes do Estado na contratação de obras públicas e na concessão de benefícios na forma de políticas específicas ${ }^{6}$.

\section{Considerações finais}

A retomada do neoliberalismo pelo Governo Temer influenciou a habitação popular, tendo em vista que rompeu com o compromisso social dos governos anteriores (Lula e Dilma). Entre outras medidas, a extinção da modalidade Entidades do PMCMV acabou por retirar direitos das camadas mais pobres da população, que há anos lutavam pelo acesso à moradia e pela casa própria e encontraram-se desamparadas. Logo, há o acentuamento da desigualdade social e da concentração de renda 7 .

A decisão de encerrar o PMCMV não foi a única ação do Governo Temer, que reduziu e sufocou a política habitacional, a ponto de mudar o sentido dos programas que envolviam o tema. A União Nacional por Moradia Popular (UNMP) denunciou o esfacelamento de canais que existiam para controle social e participação. Houve também a denúncia de ações de privatização do saneamento e de empresas públicas ${ }^{8}$.

0 corte drástico no orçamento e a ineficiência na execução das sobras de recursos liberados em 2017/2018 não atingiram a meta proposta pelo próprio Governo de 35 mil unidades habitacionais, considerando que o déficit do país já ultrapassa 7,5 milhões de moradias." Esses dados referem-se à redução do orçamento do PMCMV (Costa, 2018).

A ausência de decisão política e de sensibilidade às realidades das populações em situação de vulnerabilidade, além de impedir o atendimento das necessidades habitacionais de tais classes, traz consequências no ordenamento territorial e no planejamento urbano, pois não permite o acesso a serviços e equipamentos urbanos e infraestruturas que devem estar disponíveis para todos.

Embora não tenham sido eficazes nas grandes transformações estruturais nas políticas públicas habitacionais brasileiras, os programas habitacionais empregados pelos governos neodesenvolvimentistas de Lula e Dilma trouxeram inegáveis avanços na conquista do direito à

\footnotetext{
${ }^{6}$ A mídia brasileira noticiou esse encolhimento com chamadas, como: "Setor imobiliário perde 1 milhão de empregos com distratos em 3 anos” (Valor Econômico, 2018); “Construção civil se retrai em 2017 e segura recuperação da economia” (Globo, 2017); “Retomada imobiliária no Rio fica para 2019” (Estadão, 2017).

${ }^{7}$ Amplamente divulgado pela mídia, conforme a notícia "Movimentos ocupam Ministério das Cidades contra desmonte do MCMV entidades", divulgada no site da CUT (2018).

${ }^{8}$ Mais informações podem ser obtidas na reportagem "Movimentos de moradia protestam contra cortes de Temer na habitação", divulgada no site Brasil247 (2018).
} 
moradia pelas classes mais baixas da população. Com o avanço das políticas neoliberalizantes do Governo Temer, a tendência é uma refração nesses efeitos, de modo a excluir novamente toda a parcela mais pobre da população desses benefícios. A probabilidade é que a política habitacional venha ser mais intensamente dominada por interesses mercadológicos das classes mais altas, reproduzindo o modelo vigente anteriormente aos governos petistas.

\section{Referências}

Alvarenga, D., \& Reschilian, P. R. (2018). Financeirização da moradia e segregação socioespacial: Minha Casa, Minha Vida em São José dos Campos, Taubaté e Jacareí/SP. Urbe. Revista Brasileira de Gestão Urbana, 10(3), 473484. http://dx.doi.org/10.1590/2175-3369.010.003.ao01.

Boito, A. Jr., \& Berringer, T. (2013). Brasil: classes sociais, neodesenvolvimentismo e política externa nos governos Lula e Dilma. Revista de Sociologia e Politica, 21(47), 31-38. http://dx.doi.org/10.1590/S010444782013000300004.

Boito, A., Jr. (2012). As bases políticas do neodesenvolvimentismo. In Anais do EESP - $9^{\circ}$ Fórum de Economia. São Paulo: Fundação Getúlio Vargas. Recuperado em 13 de janeiro de 2018, de https://bibliotecadigital.fgv.br/dspace/handle/10438/16866

Bonduki, N. (1994). Origens da habitação social no Brasil. Revista Análise Social, 29(127), 711-732. Recuperado em 2 de junho de 2018, de http://analisesocial.ics.ul.pt/documentos/1223377539C9uKS3pp5Cc74XT8.pdf

Bonduki, N. (2008). Política habitacional e inclusão social no Brasil: revisão histórica e novas perspectivas no governo Lula. Revista Eletrônica de Arquitetura e Urbanismo, 1, 70-104. Recuperado em 13 de janeiro de 2018, de www.usjt.br/arq.urb/numero_01/artigo_05_180908.pdf

Bonduki, N. (2009). Do Projeto Moradia ao programa Minha Casa. Revista Teoria e Debate, 82, 8-14, Recuperado em 13 de janeiro de 2018, de https://teoriaedebate.org.br/2009/05/01/do-projeto-moradia-ao-programa-minhacasa-minha-vida/

Brasil. (1964, 16 de dezembro). Lei no 4.591 de 16 de dezembro de 1964. Dispõe sobre o condomínio em edificações e as incorporações imobiliárias. Brasília: Diário Oficial da União.

Brasil. (1988, 5 de outubro). Constituição da República Federativa do Brasil. Brasília: Diário Oficial da União.

Brasil. (1998, 3 de janeiro). Altera dispositivos da Lei no 6.019, de 3 de janeiro de 1974, que dispõe sobre o trabalho temporário nas empresas urbanas e dá outras providências e dispõe sobre as relações de trabalho na empresa de prestação de serviços a terceiros. Brasília: Diário Oficial da União. Recuperado em 13 de janeiro de 2018, de https://www.camara.leg.br

Brasil. (2001, 10 de julho). Lei no 10.257, de 10 de julho de 2001. Regulamenta os arts. 182 e 183 da Constituição Federal, estabelece diretrizes gerais da política urbana e dá outras providências. Brasília: Diário Oficial da União.

Brasil. (2016a, 15 de dezembro). Emenda Constitucional no 95, de 15 de dezembro de 2016. Altera o Ato das Disposições Constitucionais Transitórias, para instituir o Novo Regime Fiscal, e dá outras providências. Brasília: Diário Oficial da União.

Brasil. (2016b, 16 de junho). Portaria no 258, de 16 de junho de 2016. Divulga propostas apresentadas no âmbito do Programa Minha Casa Minha Vida - Entidades, operado com recursos do Fundo de Desenvolvimento Social-FDS, na forma que especifica, e dá outras providências. Brasília: Diário Oficial da União.

Brasil. (2017, 31 de março). Lei no 13.429, de 31 de março de 2017. Altera dispositivos da Lei no 6.019, de 3 de janeiro de 1974, que dispõe sobre o trabalho temporário nas empresas urbanas e dá outras providências; e dispõe sobre as relações de trabalho na empresa de prestação de serviços a terceiros. Brasília: Diário Oficial da União.

Brasil247. (2018). Movimentos de moradia protestam contra cortes de Temer na habitação. Recuperado em 13 de janeiro de 2018, de https://www.brasil247.com/pt/247/brasil/326346/Movimentos-de-moradia-protestamcontra-cortes-de-Temer-na-habita\%C3\%A7\%C3\%A3o.htm 
Bresser-Pereira, L. C. (2009). Globalização e competição. In L. C. Bresser-Pereira. O novo desenvolvimentismo (pp. 75-94). Rio de Janeiro: Campus-Elsevier. Recuperado em 13 de janeiro de 2018, de http://www.bresserpereira.org.br/Papers-cursos/Cap.3-Novo_desenvolvimentismo.pdf

Bresser-Pereira, L. C. (2011). O Brasil e o novo desenvolvimentismo. Revista Eletrônica Interesse Nacional, 4(13), 76-85.

Bresser-Pereira, L. C. (2014). A construção política do Brasil: sociedade, economia e estado desde a independência. São Paulo: Editora 34.

Bruhn, N. C. P. (2016). Investimento Direto Estrangeiro e a Política Industrial: Um estudo dos efeitos de transbordamentos em países da América Latina. (Tese de doutorado). Lavras: Programa de Pós-Graduação em Administração. Universidade Federal de Lavras.

Cardoso, A. L., \& Jaenisch, S. T. (2017). Mercado imobiliário e política habitacional nos governos de Lula e Dilma: entre o mercado financeiro e a produção habitacional subsidiada. In Anais do XVII Encontro Nacional da Associação Nacional de Pós-Graduação e Pesquisa em Planejamento Urbano e Regional (ENANPUR) (pp. 1-20). São Paulo: ENANPUR.

Carinhato, P. H. (2008). Neoliberalismo, reforma do Estado e políticas sociais nas últimas décadas do século XX no Brasil. Revista Aurora, 2(3), 37-46.

Carminati, J. G. D. O. (2010). O impacto do investimento direto estrangeiro no crescimento da economia brasileira, 1986-2009 (Dissertação de mestrado). Programa de Pós-graduação em Economia, Universidade Federal de Viçosa, Viçosa.

Central Única dos Trabalhadores - CUT. (2018). Movimentos ocupam o Ministério das Cidades contra o desmonte do Minha Casa Minha Vida Entidades. Recuperado em 13 de janeiro de 2018, de https://www.cut.org.br/noticias/movimentos-ocupam-ministerio-das-cidades-contra-desmonte-do-mcmventidades-cf64

Costa, P. (2018, 20 de outubro). Com orçamento zero em 2018, o programa Minha Casa Minha Vida é o retrato do desmonte das políticas públicas no Governo Temer. Democracia Popular. Recuperado em 20 de outubro de 2018, de http://www.democraciapopular.org.br/noticia/com-orcamento-zero-em-2018-o-programa-minha-casa-minhavida-e-o-retrato-do-desmonte-das-politicas-publicas-no-governo-temer

Estadão. (2017, 26 de novembro). Retomada imobiliária no Rio fica para 2019. Recuperado em 13 de janeiro de 2018, de https://economia.estadao.com.br/noticias/geral,retomada-imobiliaria-no-rio-fica-para2019,70002097469

Globo. (2017, 8 de outubro). Construção civil se retrai em 2017 e segura recuperação da economia. Recuperado em 13 de janeiro de 2018, de https://g1.globo.com/economia/noticia/construcao-civil-se-retrai-em-2017-e-segurarecuperacao-da-economia.ghtml

Guerreiro, I. A. (2015). Sobre a forma do programa Minha Casa, Minha Vida: o projeto de desenvolvimento contraditório do PT. In Anais do XVI ENANPUR (pp. 1-20). Belo Horizonte: ENANPUR.

Maricato, E. (2016, 8 de junho). Cortes no Minha Casa, Minha Vida vão estimular precarização da moradia. Revista Carta Capital. Recuperado em 13 de janeiro de 2018, de https://www.cartacapital.com.br/revista/903/cortes-nominha-casa-minha-vida-vao-estimular-precarizacao-da-moradia

Mattei, L. (2011). Gênese e agenda do "Novo Desenvolvimentismo brasileiro". In Anais do IV Encontro Internacional da Associação Keynesiana Brasileira. Porto Alegre: UFRGS. Recuperado em 13 de janeiro de 2018, de http://www.ppge.ufrgs.br/akb/encontros/2011/10.pdf

Paulani, L. (2008). Brasil delivery: servidão financeira e estado de emergência econômico. São Paulo: Boitempo.

Pequeno, L. R. B., \& Rosa, S. V. (2016). O Programa Minha Casa Minha Vida na Região Metropolitana de FortalezaCE: análise dos arranjos institucionais. Cadernos Metrópole, 35(35), 191-215. http://dx.doi.org/10.1590/22369996.2016-3509. 
Pereira, J. M. D. (2011). Uma breve história do desenvolvimentismo no Brasil. Cadernos do Desenvolvimento, 6(9), 121-141.

Pinho, C. E. S. (2017). Ascensão e Ocaso do Governo Dilma Rousseff à Luz das Capacidades do Estado Brasileiro: usurpação democrática e corrosão do Estado de Bem-Estar Social (2011-2016). In J. C. P. Cardodo Júnior (Ed.), Planejamento Governamental e Finanças Públicas no Brasil Contemporâneo: perspectivas críticas ao financiamento do desenvolvimento no século XXI (pp. 25-79). São Paulo: Fundação Perseu Abramo.

Rolnik, R. (2015). Guerra dos lugares: a colonização da terra e da moradia na era das finanças. São Paulo: Boitempo.

Rolnik, R. (2017, 23 de fevereiro). Mudanças no FGTS e no Minha Casa, Minha Vida: e os mais pobres?. Blog da Raquel Rolnik. Recuperado em 13 de janeiro de 2018, de https://raquelrolnik.wordpress.com/tag/minha-casaminha-vida/

Rossi, P., \& Mello, G. (2017, abril). A restauração neoliberal sob o (des)governo Temer. Revista Carta Capital. Recuperado em 13 de janeiro de 2018, de https://www.cartacapital.com.br/blogs/brasil-debate/a-restauracaoneoliberal-sob-o-des-governo-temer

Silva, R. T. F. D., Santos, A. C. D. L., Conserva, M. S., Santos, V. A., \& Bezerra, K. A. (2017). Políticas Sociais no Brasil: do neoliberalismo ao governo Temer. In Anais da Publicação VIII Jornada Internacional de Políticas Públicas. Fortaleza: UECE.

Singer, A. (2016). A (falta de) base política para o ensaio desenvolvimentista. In A. Singer \& I. Loureiro (Org.), As contradições do Lulismo: a que ponto chegamos?. São Paulo: Boitempo.

Singer, A. (2018). O lulismo em crise: um quebra-cabeça do período Dilma (2011-2016). São Paulo: Companhia das Letras.

Sitcovsky, M. (2010). Conciliações e contradições entre assistência social e trabalho: o impacto da bolsa família. In E. Mota, (Ed.), As ideologias da contrarreforma e o serviço social/organização (pp. 211-242.). Recife: Ed.

Universitária da UFPE.

Valor Econômico. (2018). Setor imobiliário perde 1 milhão de empregos com distratos em 3 anos. Recuperado em 18 de maio de 2018, de https://www.valor.com.br/empresas/5478275/setor-imobiliario-perde-1-milhao-deempregos-com-distratos-em-3-anos

Villaça, F. (2011). São Paulo: segregação urbana e desigualdade. Estudos Avançados, 25(71), 37-58. http://dx.doi.org/10.1590/S0103-40142011000100004.

Editor: Rodrigo Firmino.

Recebido: Fev. 8, 2018

Aprovado: Nov. 29, 2018 